\title{
Relation between Coronary Blood Flow and Left Ventricular Mass in Hypertension: Noninvasive Quantification of Coronary Blood Flow by Thallium-201 Myocardial Scintigraphy
}

\author{
Mareomi Hamada, Taishi Kuwahara, Yuji Shigematsu, Koji Kodama, Yuji Hara, Hidetoshi Hashida, \\ Shuntaro Ikeda, Tomoaki Ohtsuka, Shigeru Nakata*, and Kunio Hiwada
}

\begin{abstract}
This study was conducted to quantify coronary blood flow (CBF) noninvasively according to the fractionation principle and to elucidate the relation between $\mathrm{CBF}$ and left ventricular hypertrophy. CBF/ cardiac output (CO), estimated on the basis of the ratio of myocardial uptake/ total injected dose of thallium-201 (\% cardiac uptake), was determined in 14 control subjects and 40 patients with essential hypertension. CBF and CBF per $100 \mathrm{~g}$ of myocardium (unit CBF) were calculated according to the following formulas: $\mathrm{CBF}=\%$ cardiac uptake $\times \mathrm{CO}$, and unit $\mathrm{CBF}=(\mathrm{CBF} / \mathrm{LVM}) \times 100$, where $\mathrm{CO}$ and left ventricular mass (LVM) are echocardiographically determined. There was good reproducibility of \% cardiac uptake $(r=0.983, p<0.0001)$. Percent cardiac uptake was greater in hypertensive patients $(4.65 \pm 1.44 \%)$ than in control subjects $(3.64 \pm 0.64 \%)$, and there was a positive correlation between $\%$ cardiac uptake and LVM. CBF $(\mathrm{ml} / \mathrm{min})$ was greater in hypertensive patients $(240.7 \pm 80.5)$ than in control subjects $(194.9 \pm 36.9)$, but unit $\mathrm{CBF}(\mathrm{ml} / \mathrm{min} / 100 \mathrm{~g})$ was less in hypertensive patients $(102.2 \pm$ 26.7) than in control subjects $(150.3 \pm 30.5)$. Multiple regression analyses showed that LVM was the most potent independent predictor of resting CBF in hypertension. Our results indicate that CBF, determined by thallium-201 myocardial scintigraphy, increases parallel to the increase in LVM, but unit CBF decreases even in the resting condition in patients with essential hypertension. (Hypertens Res 1998; 21: 227-234)
\end{abstract}

Key Words: coronary blood flow, thallium-201 myocardial scintigraphy, left ventricular mass, left ventricular hypertrophy, essential hypertension

Left ventricular hypertrophy associated with hypertension is not only a physiological adaptation to sustained arterial hypertension, but also a pathologic process leading to heart failure $(1,2)$. In addition, left ventricular mass is an independent risk factor for cardiovascular diseases $(3,4)$, and increased left ventricular mass predicts increased cardiovascular morbidity and mortality $(4,5)$. However, why left ventricular hypertrophy predisposes patients to morbid events is not fully understood. Many studies have shown that coronary blood flow (CBF) reserve is reduced in hypertensive patients with left ventricular hypertrophy (6-13). Thus, changes in the coronary circulation associated with left ventricular hypertrophy seem to be related to cardiovascular morbidity and mortality. However, only a few studies have quantified $\mathrm{CBF}$ in patients with hypertension $(6,7,12)$ because of the complexity and invasiveness of conventional techniques for measurement of CBF. CBF can be determined noninvasive- ly by positron-emission tomography with nitrogen13-ammonia (14), but this method is not in general use. Very recently, Kazàkovà et al. (13) determined the coronary flow reserve by transesophageal Doppler echocardiography. This method, however, measures only flow velocity and not absolute volumetric flow.

Sapirstein (15) first indicated that the fractional distribution of K-42 or Rb- 86 corresponded to the fractional distribution of the cardiac output $(\mathrm{CO})$ in rats and dogs. In addition, Donato et al. (16) confirmed that CBF in man could be accurately determined on the basis of the fractional distribution of these two tracers. These findings suggest that thallium-201, which is biologically similar to potassium, can be utilized to measure CBF. In fact, Ishii et al. (17) and Owada et al. (18) have already evaluated myocardial blood flow by thallium-201 myocardial scintigraphy. In addition, experiments in dogs have confirmed a close linear relationship between

From the Second Department of Internal Medicine, Ehime University School of Medicine, Ehime, Japan, and * Department of Radiology, Ehime University School of Medicine, Ehime, Japan.

Address for Reprints: Mareomi Hamada, M.D., The Second Department of Internal Medicine, Ehime University School of Medicine, Shigenobu, Onsen-gun, Ehime 791-0295, Japan.

Received September 11, 1997; accepted in revised form August 31, 1998. 
the distribution of thallium-201 in myocardium and direct measurements of regional myocardial blood flow (19).

This study was designed to confirm the reliability of thallium-201 myocardial scintigraphy in determining $\mathrm{CBF}$ and to elucidate the relation between $\mathrm{CBF}$ and left ventricular hypertrophy in patients with essential hypertension.

\section{Methods}

Subjects

The study group comprised 54 subjects who were admitted to our clinic. The subjects were divided into 2 groups: 14 control subjects and 40 patients with essential hypertension. The control subjects consisted of 10 men and 4 women who underwent cardiac catheterization because of chest pain of unknown etiology. All control subjects had normal coronary arteriograms and a negative response to vasospastic stimuli. None had a history of hypertension or had any abnormalities on physical examination, electrocardiography, echocardiography, or chest radiography. The mean age of this group was $45 \pm 8 \mathrm{yr}$.

The 40 patients with essential hypertension consisted of 27 men and 13 women with satisfactory echocardiograms. Patients who had secondary hypertension, valvular heart disease, coronary artery disease, diabetes mellitus, or bundle branch block were excluded from this study. Nine patients in this group received cardiac catheterization because of chest pain, and their coronary arteriograms showed no significant stenosis. Hypertension was defined as a systolic pressure $\geq 140 \mathrm{mmHg}$, a diastolic pressure $\geq 90 \mathrm{mmHg}$, or both, in the outpatient clinic (20).

All subjects received a diet containing $7 \mathrm{~g}$ of $\mathrm{NaCl}$ per $\mathrm{d}$, and all medications were discontinued on admission. After a 1-wk stabilization period, echocardiographic and thallium-201 myocardial scintigraphic examinations were performed.

Informed consent for the study was obtained from each patient.

\section{Echocardiography}

Echocardiographic studies were performed using an SSD-9000 echocardiograph with a $3.5 \mathrm{MHz}$ transducer (ALOKA Inc, Tokyo, Japan). Interventricular septal thickness, left ventricular posterior wall thickness, and left ventricular internal dimensions at end-diastole and end-systole were measured according to the criteria of the American Society of Echocardiography (21). Left ventricular fractional shortening was also calculated as an index of systolic function. In addition, left ventricular mass was calculated by the method of Devereux and Reichek (22) and was divided by body surface area to obtain left ventricular mass index. $\mathrm{CO}$ was echocardiographically determined as reported previously (23), using the method of Teichholz et al. (24). Echocardiographic studies were performed within $2 \mathrm{~d}$ of thallium-201 myocardial scintigraphic studies.

\section{Determination of $C B F$}

The indicator fractionation principle of Sapirstein (15) indicates that the fractional distribution of K-42 corresponds to the fractional distribution of $\mathrm{CO}$. Thus, a ratio of $\mathrm{CBF} / \mathrm{CO}, \%$ cardiac uptake, can be determined using thallium-201, which is biologically similar to potassium (25).

Thallium-201 myocardial scintigraphy was performed 1 or $2 \mathrm{wk}$ after drug withdrawal. On the day of thallium-201 myocardial scintigraphy, subjects were instructed to have no breakfast and to continue fasting until the end of the last imaging session. Ten minutes after and $5 \mathrm{~h}$ after intravenous injection of thallium-201 (4.9 to $6.2 \mathrm{mCi}$ ), early and delayed single photon emission computerized tomographic (SPECT) images were obtained, respectively. The SPECT system (GCA 9300, Toshiba, Tokyo and Scintipac 2400, Shimadzu, Kyoto, Japan) consisted of a triple-headed digital gamma camera equipped with high-resolution, low-energy, parallel hole collimators. Energy discrimination was provided by a $15 \%$ window centered on the $70-\mathrm{keV}$ photopeak. Projection images were acquired for 90 $\mathrm{s}$ each at 10-degree increments over a 360-degree orbit and were recorded at a digital resolution of $128 \times 128$. A region of interest (ROI) was set on the whole heart and a rectangular ROI, usually 10 $\times 20$ pixels in size, was placed on the left upper lung in the anterior projection image obtained by the SPECT study.

Percent cardiac uptake ( $\mathrm{CBF} / \mathrm{CO}$ ratio) was calculated by the following formula: \% cardiac uptake $=($ myocardial uptake of thallium-201/total injected dose of thallium-201) $\times 100$. To calculate the thallium-201 myocardial uptake, a rectangular solid phantom filled with $200 \mathrm{ml}$ of thallium-201 solution was placed in the center of rotation in air, and anterior and left lateral planar images were obtained in the same acquisition condition as the projection images in the SPECT study. A crosscalibration factor between the planar counts (counts per $\mathrm{min}$ ) and the count of radioactivity (megabecquerels, $\mathrm{MBq}$ ) was determined.

Myocardial uptake of thallium-201 was measured to subtract lung counts from whole heart counts in ROI on the anterior projection image. The subtracted lung counts were calculated using the lung counts in ROI on the anterior projection image and the lateral length of the lung behind the heart. The count of the heart was converted from counts to $\mathrm{MBq}$ using the cross-calibration factor. The crosscalibration factor was as follows: $Y=1.329 \times 10^{-4}$ $X-0.782$, where $Y$ is the amount of radioactivity and $X$ is the number of counts per min. The total injected dose $(\mathrm{MBq})$ in each subject was calculated on the basis of the difference between the radioactivities of the syringe before and after injection.

Figure 1 shows the reproducibility of $\%$ cardiac uptake in 11 patients with essential hypertension between the first examination and the second one (40 $\pm 3 \mathrm{~d}$ after the first examination). There was a very good correlation between the results of the two examinations $(r=0.983, p<0.0001)$.

$\mathrm{CBF}$ was also determined noninvasively by the 


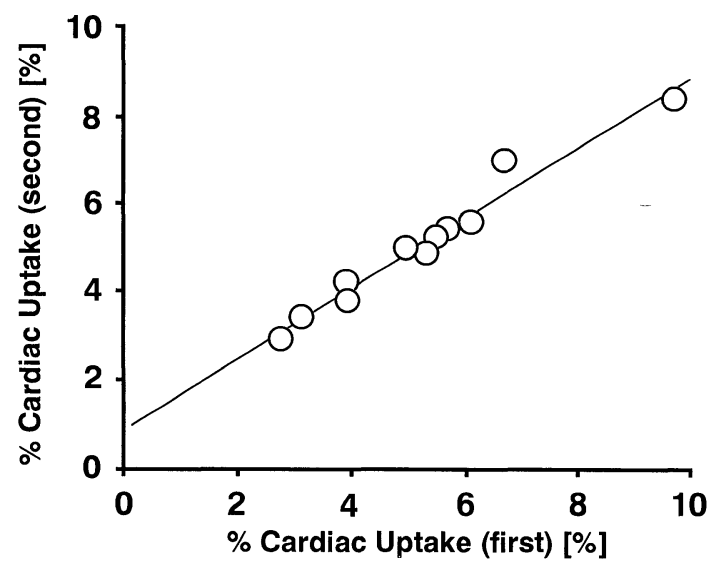

Fig. 1. Reproducibility of $\%$ cardiac uptake as determined by thallium-201 myocardial scintigraphy. There was a very good correlation between the first examination and the second one (performed $40 \pm 3 d$ after the first examination) $(\mathrm{y}=0.806 \mathrm{x}+0.84, \mathrm{r}=0.983, \mathrm{p}<0.0001)$.

following formula: $\mathrm{CBF}(\mathrm{ml} / \mathrm{min})=\%$ cardiac uptake $\times \mathrm{CO}$, where \% cardiac uptake is determined by thallium-201 myocardial scintigraphy and $\mathrm{CO}$ is determined by echocardiography, respectively.

$\mathrm{CBF}$ per unit of $100 \mathrm{~g}$ of myocardium (unit CBF) was also calculated by the following formula: unit $\mathrm{CBF}(\mathrm{ml} / \mathrm{min}$ per $100 \mathrm{~g})=(\mathrm{CBF} /$ left ventricular mass $)$ $\times 100$.

Comparison of \% Cardiac Uptake Determined by Thallium-201 Myocardial Scintigraphic Method with that Determined by Invasive Method

To examine the validity of thallium-201 myocardial scintigraphy in assessing the \% cardiac uptake, $\%$ cardiac uptake measured by scintigraphy was compared with that determined invasively by the Doppler guide wire method. CBF was determined by the following formula as described by Labovitz et al. (26): $\mathrm{CBF}=\mathrm{TVi} \times$ heart rate $\times \mathrm{CSA}$, where $\mathrm{TVi}$ is time velocity integral (shaded area in Fig. 2) and CSA is cross-sectional area of the coronary artery at the point of measurement. CSA was calculated by the formula $(D / 2)^{2} \times \pi$, where $D$ is the measured internal diameter. In this study, intracoronary flow velocity was measured at the ostium of the left coronary artery and that of the right coronary artery with a 0.014-inch Doppler angioplasty guide wire (Flowire, Cardiometrics, Inc., Mountain View, Calif., USA); the CBF of each artery was then calculated according to the above formula. Percent cardiac uptake was calculated as a ratio of the sum of CBF in left and right coronary arteries to $\mathrm{CO}$ as determined by the thermodilution method.

Figure 3 shows a comparison of $\%$ cardiac uptake determined by thallium-201 myocardial scintigraphy with that determined by a combination of the Doppler guide wire method and the thermodilution method in 23 subjects. These subjects included 14 patients with chest pain syndrome, 3 with vasospastic angina, 2 with hypertrophic cardiomyopathy, 2

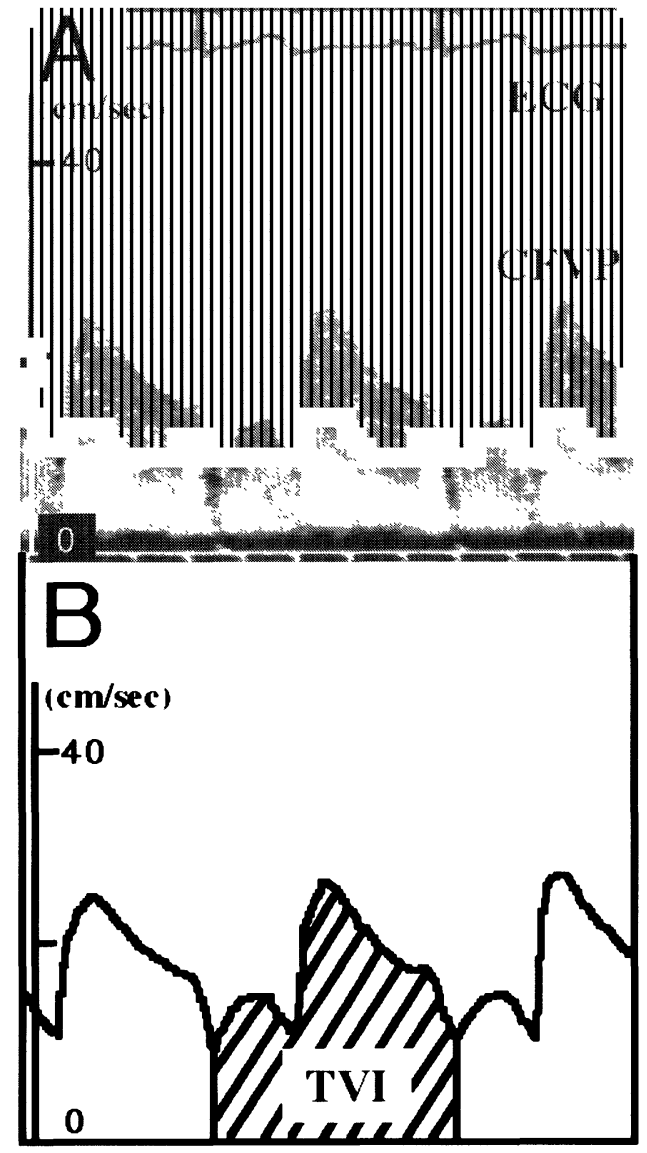

Fig. 2. Doppler spectral tracing showing measurement of time velocity integral (TVI). ECG, electrocardiogram; CFVP, coronary flow velocity pattern.

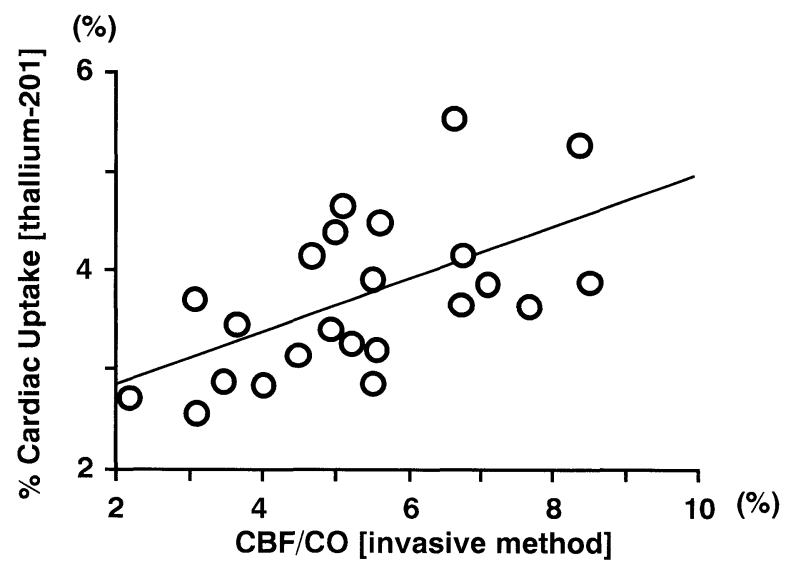

Fig. 3. Relation between \% cardiac uptake as measured by thallium-201 myocardial scintigraphy and $\mathrm{CBF} / \mathrm{CO}$ ratio as measured by a combination of the Doppler guide wire method and thermodilution method. There was a significant correlation between the results obtained by the two methods $(\mathrm{y}=0.253 \mathrm{x}+2.349, \mathrm{r}=0.560, \mathrm{p}<0.01)$. 
Table 1. Hemodynamic and Echocardiographic Data

\begin{tabular}{lcc}
\hline & $\begin{array}{c}\text { Normotensive } \\
\text { control subjects }\end{array}$ & $\begin{array}{c}\text { Essential } \\
\text { hypertensives }\end{array}$ \\
\hline$n$ & 14 & 40 \\
HR (bpm) & $66 \pm 9$ & $69 \pm 9$ \\
SBP (mmHg) & $121 \pm 12$ & $170^{\dagger} \pm 16$ \\
DBP (mmHg) & $71 \pm 4$ & $101^{\dagger} \pm 9$ \\
LVDd (mm) & $49.1 \pm 3.6$ & $51.7 \pm 5.4$ \\
LVDs (mm) & $29.1 \pm 3.3$ & $34.3^{*} \pm 6.3$ \\
IVST (mm) & $6.3 \pm 0.8$ & $9.9^{*} \pm 3.0$ \\
PWT (mm) & $8.3 \pm 0.9$ & $11.9^{\dagger} \pm 3.2$ \\
LVM (g) & $133.0 \pm 28.5$ & $265.6^{*} \pm 120.4$ \\
LVMI (g/m $\left.{ }^{2}\right)$ & $89.1 \pm 19.2$ & $154.4^{*} \pm 62.6$ \\
FS $(\%)$ & $41.5 \pm 4.2$ & $33.8^{*} \pm 6.9$ \\
RPP $(\mathrm{bpm} \cdot \mathrm{mmHg})$ & $7,948 \pm 1,145$ & $12,119^{\dagger} \pm 1,590$ \\
\hline
\end{tabular}

HR, heart rate; SBP, systolic blood pressure; DBP, diastolic blood pressure; LVDd, left ventricular end-diastolic dimension; LVDs, left ventricular end-systolic dimension; IVST, interventricular septal thickness; PWT, posterior wall thickness; LVM, left ventricular mass; I, index; FS, fractional shortening; RPP, rate pressure product.

${ }^{*} p<0.001,{ }^{\dagger} p<0.0001 v s$. normotensive control subjects.

Table 2. Myocardial Scintigraphically Determined Data and $\mathrm{CBF}$

\begin{tabular}{lcc}
\hline & $\begin{array}{c}\text { Normotensive } \\
\text { control subjects }\end{array}$ & $\begin{array}{c}\text { Essential } \\
\text { hypertensives }\end{array}$ \\
\hline \% Cardiac uptake of $\mathrm{Tl}(\%)$ & $3.64 \pm 0.64$ & $4.65^{*} \pm 1.44$ \\
CO $(1 / \mathrm{min})$ & $5.38 \pm 0.62$ & $5.36 \pm 0.76$ \\
CI $\left(1 / \mathrm{min} / \mathrm{m}^{2}\right)$ & $3.61 \pm 0.39$ & $3.18^{\dagger} \pm 0.46$ \\
$\mathrm{CBF}(\mathrm{ml} / \mathrm{min})$ & $194.9 \pm 36.9$ & $240.7^{*} \pm 80.5$ \\
CBFI $\left(\mathrm{ml} / \mathrm{min} / \mathrm{m}^{2}\right)$ & $132.1 \pm 32.7$ & $142.2 \pm 46.0$ \\
Unit CBF $(\mathrm{ml} / \mathrm{min} / 100 \mathrm{~g})$ & $150.3 \pm 30.5$ & $102.2^{\ddagger} \pm 26.7$ \\
\hline
\end{tabular}

Tl, thallium; CO, cardiac output; CI, cardiac index; CBF, coronary blood flow; I, index. ${ }^{*} p<0.05,{ }^{\dagger} p<0.01,{ }^{\ddagger} p<$ $0.0001 v s$. normotensive control subjects.

with essential hypertension, and 2 with aortic insufficiency in whom coronary angiography showed no significant stenosis (mean age, $60 \pm 10 \mathrm{yr}$ ). Both methods for the estimation of \% cardiac uptake were performed within a week. As shown in Fig. 3, there was a very good correlation between the results obtained by the two methods.

\section{Statistics}

Data are expressed as means $\pm \mathrm{SD}$ in the text and tables. Group means were compared by the unpaired $t$-test. Correlations were sought using leastsquares linear regression analyses. To determine the independent predictors of the individual factor in CBF, multiple linear regression analysis was used. $p$ $<0.05$ was considered to indicate statistical significance.
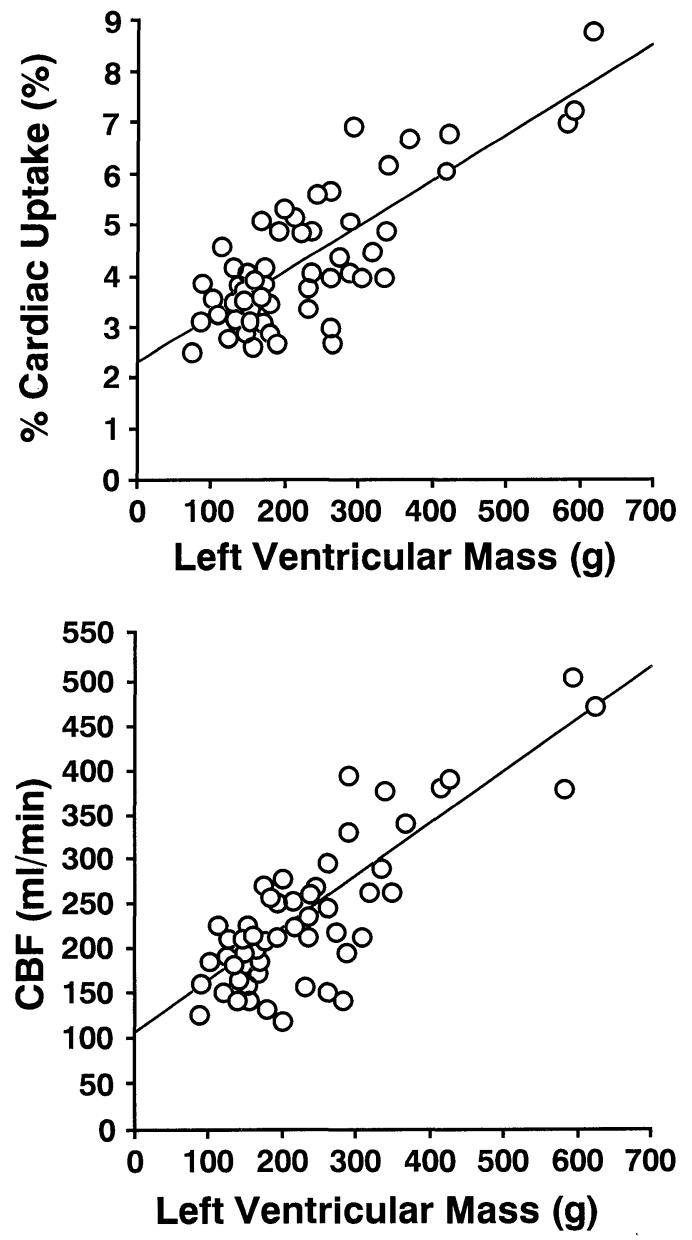

Fig. 4. Relation between \% cardiac uptake and left ventricular mass (upper) and that between CBF and left ventricular mass (lower). Both \% cardiac uptake and CBF correlated positively with left ventricular mass $(\mathrm{y}=0.009 \mathrm{x}$ $+2.314, \mathrm{r}=0.791, \mathrm{p}<0.0001$, and $\mathrm{y}=0.598 \mathrm{x}+101.188, \mathrm{r}$ $=0.827, \mathrm{p}<0.0001)$.

\section{Results}

Clinical Profiles of the Subjects

Table 1 shows the clinical profiles of the subjects and the echocardiographically determined variables. There was no significant difference in heart rate between control subjects and patients with essential hypertension.

There was no significant difference in left ventricular end-diastolic dimension between control subjects and patients with essential hypertension, but end-systolic dimension was greater in essential hypertensive patients than in control subjects. Interventricular septal thickness, left ventricular posterior wall thickness, left ventricular mass, and left ventricular mass index were significantly greater in hypertensive patients than in control subjects. Fractional shortening was significantly less in hypertensive patients than in control subjects. Rate-pressure product was significantly greater in hypertensive pa- 
Table 3. Multiple Linear Regression Analyses of the Independent Predictors of CBF

\begin{tabular}{lcccc}
\hline \multicolumn{1}{c}{ Independent variables } & Coefficient & Standard error & $t$ & $p$ \\
\hline Age & & 0.649 & -1.716 & 0.0996 \\
Body surface area & & 57.716 & -0.781 & 0.4428 \\
Left ventricular mass & 0.509 & 0.116 & 4.377 & 0.0002 \\
Heart rate & & 5.666 & 0.390 & 0.7003 \\
Systolic blood pressure & & 2.606 & 1.405 & 0.1735 \\
Diastolic blood pressure & -4.355 & 1.763 & -2.470 & 0.0214 \\
Rate pressure product & & 0.036 & -0.292 & 0.7731 \\
\hline
\end{tabular}

Multivariate predictor of $\mathrm{CBF}: \mathrm{CBF}=0.509$ (left ventricular mass) -4.355 (diastolic blood pressure) +30.986 ; Multiple $\mathrm{R}$ was 0.852 , and squared multiple $\mathrm{R}$ was 0.727 .

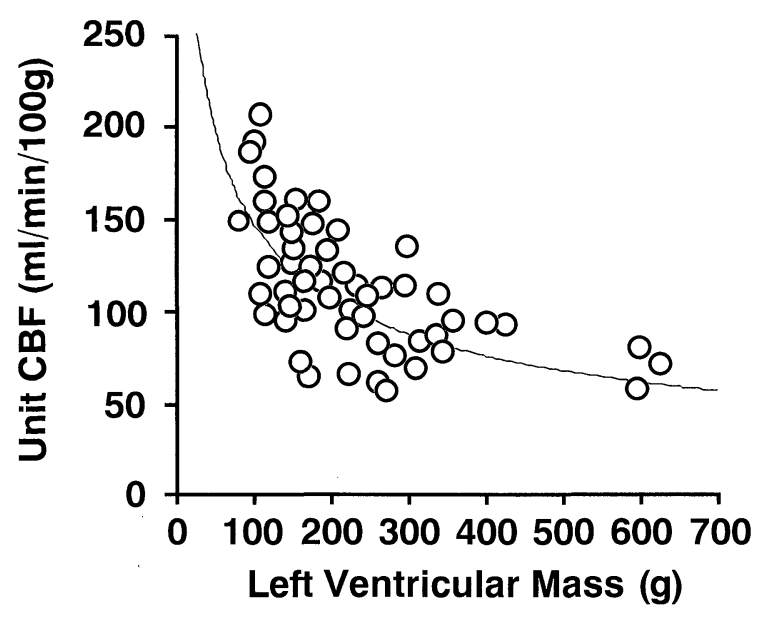

Fig. 5. Relation between unit $C B F$ and left ventricular mass. The correlation between unit $C B F$ and left ventricular mass was calculated using a logistic fit. There was a negative correlation between the two variables $(\mathrm{y}=$ $\left.1233.058 \mathrm{x}^{0.454}, \mathrm{r}=-0.686, \mathrm{p}<0.0001\right)$.

tients than in control subjects.

\section{Percent Cardiac Uptake, $\mathrm{CO}$ and $\mathrm{CBF}$}

As shown in Table 2, \% cardiac uptake was significantly greater in hypertensive patients than in control subjects. There was no significant difference in $\mathrm{CO}$ between the 2 groups, but cardiac index was significantly less in hypertensive patients than in control subjects. $\mathrm{CBF}$ was significantly greater in hypertensive patients than in control subjects.

Figure 4 shows the relation between $\%$ cardiac uptake and left ventricular mass (upper panel) and the relation between $\mathrm{CBF}$ and left ventricular mass (lower panel). Both \% cardiac uptake and CBF correlated positively with left ventricular mass. In addition, CBF correlated positively with rate-pressure product $(r=0.597, p<0.0001)$.

\section{Relations between Unit CBF and Left Ventricular} Mass or Left Ventricular Function

Table 2 shows unit CBF in the 2 groups. Unit CBF was significantly less in patients with essential hypertension than in control subjects. There was a negative correlation between unit $\mathrm{CBF}$ and left ventricular mass as shown in Fig. 5. In addition, there was a positive correlation between unit $\mathrm{CBF}$ and fractional shortening $(r=0.575, p<0.0001)$.

\section{Multiple Regression Analyses of the Independent Predictors of $C B F$}

To determine which clinical variables could predict CBF independently, multiple linear regression analyses were performed, using left ventricular mass, heart rate, systolic blood pressure, diastolic blood pressure, and rate-pressure product. As shown in Table 3 , the most potent predictor was left ventricular mass, followed by diastolic blood pressure; the other variables had no significant influence on $\mathrm{CBF}$.

\section{Discussion}

The present study for the first time quantified CBF noninvasively, excluding attempts by positron-emission tomography, using a combination of thallium201 myocardial scintigraphy and echocardiography. Resting \% cardiac uptake as determined by thallium-201 myocardial scintigraphy remained constant for at least $40 \mathrm{~d}$. Our results indicate that \% cardiac uptake and CBF in essential hypertension correlate positively with left ventricular mass, and that unit CBF correlates negatively with left ventricular mass. In addition, multiple regression analyses indicated that left ventricular mass was the most potent predictor of $\mathrm{CBF}$ at rest in essential hypertension.

Noninvasive CBF Quantification Using Thallium-201 Myocardial Scintigraphy

In 1958, Sapirstein (15) reported that regional blood flow could be measured with the use of K-42 or Rb86. This hypothesis was based on the physical properties of these two tracers, i.e., that the initial partition of a single bolus dose of these ions was proportional to the distribution of $\mathrm{CO}$, and that this distribution was maintained for a certain time after completion of the first circulation. However, these two tracers have not been used clinically, because only a low percentage of the total dose is transferred to the myocardium and because hepatic and gastric uptake are high (27). As compared with 
these two tracers, the percentage of the total dose of thallium-201 concentrated in the myocardium is about 2-fold higher (27), and the hepatic and gastric uptake of thallium-201 is far less than that of either K-42 or Rb-86 (27). Thus, thallium-201 can be used to measure regional blood flow, especially $\mathrm{CBF}(19$, 28).

CBF estimated noninvasively was compared with that determined by the Doppler guide wire method (26). To minimize the time difference between the recordings by echocardiography and thallium-201 myocardial scintigraphy, \% cardiac uptake determined by thallium-201 myocardial scintigraphy and $\mathrm{CBF} / \mathrm{CO}$ ratio determined invasively were compared. Considering that the two methods were not performed simultaneously, \% cardiac uptake as estimated by thallium-201 myocardial scintigraphy may correlate well with $\mathrm{CBF} / \mathrm{CO}$ ratio as estimated by a combination of the Doppler guide wire method and thermodilution method.

Guyton (29) reported that the resting CBF in human beings averages approximately $225 \mathrm{ml} / \mathrm{min}$. Czernin et al. (30) measured CBF by positron emission tomography with nitrogen-13-ammonia. In their data, resting CBF in normal subjects was (76 $\pm 17) \times 3 \mathrm{ml} / \mathrm{min}$ in subjects younger than $50 \mathrm{yr}$ and $(92 \pm 25) \times 3 \mathrm{ml} / \mathrm{min}$ in those older than $50 \mathrm{yr}$. CBF in our study was $194.9 \pm 36.9 \mathrm{ml} / \mathrm{min}$ in control subjects. Given that body surface area is greater in Americans than in Japanese, noninvasively determined CBF in our study closely approximates previously reported data. Thus, our newly devised method can be used to measure $\mathrm{CBF}$ in a clinical setting.

\section{Relation between \% Cardiac Uptake and Left Ven- tricular Mass}

Resting CBF in normal controls is approximately $4 \%$ of CO (29). Percent cardiac uptake in normal controls in previous studies by Ishii et al. (17) and Owada et al. (18) was $4.0 \pm 0.5 \%$ and $3.49 \pm$ $0.45 \%$, respectively, as compared with $3.64 \pm$ $0.64 \%$ in our study. As shown in Fig. 1,\% cardiac uptake at rest is highly reproducible. These results indicate that $\%$ cardiac uptake as determined by thallium-201 myocardial scintigraphy is clinically applicable.

The results of our study indicate a strong correlation between \% cardiac uptake and left ventricular mass. Given that resting $\mathrm{CO}$ remained within normal limits in almost all hypertensive patients in our study, an increase in \% cardiac uptake indicates compensation of $\mathrm{CBF}$ in association with the increase in left ventricular mass. However, \% cardiac uptake cannot increase without limitation. Resting $\mathrm{CO}$ usually remains constant and an excessive increase in \% cardiac uptake decreases the share of $\mathrm{CO}$ to other organs. Thus, there may be limits of CBF compensation in hypertensive patients with left ventricular hypertrophy. This inability to increase CBF without limitation may be closely related to the fact that myocardial hypertrophy in hypertension changes from a physiological adaptation to a pathologic process.
Relation between CBF, CBF per Unit Mass, and Left Ventricular Mass

CBF in our study included both the left and right ventricles, although muscle mass measures only the left ventricle. Thus, unit CBF of the left ventricle in our study was slightly overestimated.

The most important finding in our study is that unit $\mathrm{CBF}$ is less even at rest in hypertensive patients than in control subjects, although $\mathrm{CBF}$ is greater in hypertensive patients than in control subjects. In addition, unit CBF decreases parallel to the increase in left ventricular mass. Our results differ from previous findings that the resting CBF per unit muscle mass in patients with left ventricular hypertrophy is normal $(6,7,31)$. Of these studies, Pichard et al. (7) reported that CBF per $100 \mathrm{~g}$ of myocardium in patients with ventricular hypertrophy remained normal, whereas the calculated CBF per $100 \mathrm{~g}$ of myocardium was $116.3 \mathrm{ml} / \mathrm{min}$ per 100 $\mathrm{g}$ in the control group, 92.1 in the mild hypertrophy group, and 83.4 in the severe hypertrophy group, respectively. These results agree with our data. Very recently, Motz and Strauer (12) reported that baseline CBF, determined invasively, in hypertensive patients with left ventricular hypertrophy was $82.9 \pm 19.9 \mathrm{ml} / \mathrm{min}$ per $100 \mathrm{~g}$, which was less than that in not only the control subjects but also the hypertensive patients in our study. Thus, it appears likely that unit $\mathrm{CBF}$ in hypertensive patients is low even at rest.

The results of our study indicate that hypertrophy as a physiological adaptation to hypertension may be accompanied by progressive myocardial ischemia. This myocardial ischemia may be closely related to left ventricular dysfunction, which leads to heart failure (2). In fact, fractional shortening in our patients correlated positively with unit CBF, but not with CBF. In view of the coronary circulation in hypertension, the concept that left ventricular mass is an independent risk factor for various cardiovascular diseases is acceptable $(3,4)$. In fact, multiple regression analyses in our study clearly showed that the most potent predictor of CBF in hypertension was left ventricular mass. Our results may also explain the redistribution seen on stress testing with thallium-201 myocardial scintigraphy (10) and the chest pain at rest without significant stenosis of the coronary arteries in hypertension. Electrocardiographic evidence of negative $\mathrm{T}$ waves in advanced hypertension may reflect the limits of CBF compensation (32). As reported by Antony et al. (11), the normalization of arterial pressure with persistent left ventricular hypertrophy was associated with a marked impairment in coronary reserve. Thus, the best way to increase unit CBF is the regression of left ventricular hypertrophy.

\section{Limitations of the Study}

The present study has several limitations. First, we have no data on CBF measured simultaneously by our noninvasive method and an invasive method. However, the CBF/CO ratio determined invasively closely correlated with the \% cardiac uptake determined on a different day. This finding suggests that 
the method used to noninvasively determine $\mathrm{CBF}$ in this study is clinically useful. A second limitation is the time difference between the determinations of $\%$ cardiac uptake by thallium-201 myocardial scintigraphy and $\mathrm{CO}$ by echocardiography. However, given that the \% cardiac uptake at rest remained unchanged for more than 1 mo, changes in $\mathrm{CBF}$ associated with the time difference between the measurement of $\%$ cardiac uptake and that of $\mathrm{CO}$ may be negligible.

\section{References}

1. Grossman W: Cardiac hypertrophy: useful adaptation or pathologic process? Am J Med 1980; 69: 576-584.

2. Hamada M, Ohtani T, Suzuki M, et al: Is left ventricular systolic dysfunction in hypertensive patients with heart failure normalized by long-term antihypertensive therapy? J Cardiol 1993; 23: 165-175.

3. Levy D, Garrison RJ, Savage DD, Kannel WB, Castelli WP: Prognostic implications of echocardiographically determined left ventricular mass in the Framingham heart study. $N$ Engl J Med 1990; 322: 1561-1566.

4. Koren MJ, Devereux RB, Casale PN, Savage DD, Laragh JH: Relation of left ventricular mass and geometry to morbidity and mortality in uncomplicated essential hypertension. Ann Intern Med 1991; 114: 345-352.

5. Casale PN, Devereux RB, Milner M, et al: Value of echocardiographic measurement of left ventricular mass in predicting cardiovascular morbid events in hypertensive men. Ann Intern Med 1986; 105: 173178.

6. Strauer B-E: Ventricular function and coronary hemodynamics in hypertensive heart disease. Am J Cardiol 1979; 44: 999-1006.

7. Pichard AD, Gorlin R, Smith H, Ambrose J, Meller $\mathrm{J}$ : Coronary flow studies in patients with left ventricular hypertrophy of the hypertensive type. Evidence for an impaired coronary vascular reserve. $\mathrm{Am}$ J Cardiol 1981; 47: 547-554.

8. Marcus ML, Doty DB, Hiratzka LF, Wright CB, Eastham CL: Decreased coronary reserve: a mechanism for angina pectoris in patients with aortic stenosis and normal coronary arteries. N Engl J Med 1982; 307: 1362-1367.

9. Hoffman JIE: A critical view of coronary reserve. Circulation 1987; 75 (Suppl I): I-6-I-11.

10. Houghton JL, Frank MJ, Carr AA, von Dohlen TW, Prisant LM: Relations among impaired coronary flow reserve, left ventricular hypertrophy and thallium perfusion defects in hypertensive patients without obstructive coronary artery disease. J Am Coll Cardiol 1990; 15: 43-51.

11. Antony I, Nitenberg A, Foult J-M, Aptecar E: Coronary vasodilator reserve in untreated and treated hypertensive patients with and without left ventricular hypertrophy. J Am Coll Cardiol 1993; 22: 514-520.

12. Motz W, Strauer BE: Improvement of coronary flow reserve after long-term therapy with enalapril. Hypertension 1996; 27: 1031-1038.

13. Kozàkovà $M$, Palombo $C$, Pratali L, Pittella G, Galetta F, L'Abbate A: Mechanisms of coronary flow reserve impairment in human hypertension: an integrated approach by transthoracic and transesophageal echocardiography. Hypertension 1997; 29: 551-559.
14. Muzik O, Beanlands RSB, Hutchins GD, Mangner TJ, Nguyen N, Schwaiger M: Validation of nitrogen13-ammonia tracer kinetic model for quantification of myocardial blood flow using PET. J Nucl Med 1993; 34: 83-91.

15. Sapirstein LA: Regional blood flow by fractional distribution of indicators. Am J Physiol 1958; 193: 161168.

16. Donato L, Bartolomei G, Giordani R: Evaluation of myocardial blood perfusion in man with radioactive potassium or rubidium and precordial counting. Circulation 1964; 29: 195-203.

17. Ishii Y, Kanbara H, Yonekura Y, et al: Myocardial scintigraphy with ${ }^{201} \mathrm{Tl}$ and quantitative assessment of myocardial blood flow. Jpn Nucl Med 1976; 13: 787797 (in Japanese with English Abstract).

18. Owada K, Tsukahara Y, Abe H, et al: Clinical studies on the thallium-201 myocardial scintigraphy in the patients with ischemic heart diseases: studies in organ distribution of thallium-201 and in the measurement of myocardial blood flow. Jpn Nucl Med 1980; 17: 891-899 (in Japanese with English Abstract).

19. Nielsen AP, Morris KG, Murdock R, Bruno FP, Cobb FR: Linear relationship between the distribution of thallium-201 and blood flow in ischemic and nonischemic myocardium during exercise. Circulation 1980; 61: 797-801.

20. World Health Organization: Report of a WHO expert committee. Hypertension control. World Health Organ Tech Rep Ser 1996; 862: 2-3.

21. Sahn DJ, DeMaria A, Kisslo J, Weyman A: Recommendations regarding quantitation in M-mode echocardiography: results of a survey of echocardiographic measurements. Circulation 1978; 58: 10721083.

22. Devereux RB, Reichek N: Echocardiographic determination of left ventricular mass in man: anatomic validation of the method. Circulation 1977; 55: 613618.

23. Hamada M, Shigematsu Y, Mukai M, Kazatani Y, Kokubu T, Hiwada K: Blood pressure response to the Valsalva maneuver in pheochromocytoma and pseudopheochromocytoma. Hypertension 1995; 25: 266-271.

24. Teichholz LE, Kreulen T, Herman MV, Gorlin R: Problems in echocardiographic volume determinations: echocardiographic-angiographic correlations in the presence or abscence of asynergy. Am J Cardiol 1976; 37: 7-14.

25. Lebowitz E, Greene MW, Fairchild R, et al: Thallium-201 for medical use. I. J Nucl Med 1975; 16: 151-155.

26. Labovitz AJ, Anthonis DM, Cravens TL, Kern MJ: Validation of volumetric flow measurements by means of a Doppler-tipped coronary angioplasty guide wire. Am Heart J 1993; 126: 1456-1461.

27. Strauss HW, Harrison K, Langan JK, Lebowitz E, Pitt B: Thallium-201 for myocardial imaging: relation of thallium-201 to regional myocardial perfusion. Circulation 1975; 51: 641-645.

28. Mueller TM, Marcus ML, Ehrhardt JC, Chaudhuri T, Abboud FM: Limitations of thallium-201 myocardial perfusion scintigrams. Circulation 1976; 54: 640646.

29. Guyton AC: The coronary circulation and ischemic heart disease. in Guyton AC (ed): Textbook of Medical Physiology (7th ed). Philadelphia, W.B. Saunders Co., 1986, pp295-304.

30. Czernin J, Müller P, Chan S, et al: Influence of age and hemodynamics on myocardial blood flow and flow reserve. Circulation 1993; 88: 62-69. 
31. Marcus ML, Mueller TM, Gascho JA, Kerber RE: Effects of cardiac hypertrophy secondary to hypertension on the coronary circulation. Am J Cardiol 1979; 44: 1023-1028.

32. Ohtani T, Hamada M, Shigematsu Y, et al: Clinical significance of negative $\mathrm{T}$ wave in precordial leads on electrocardiogram in essential hypertensives: its correlation with the left ventricular mass. Hypertens Res 1993; 16: 191-195. 